\title{
A New Gas Carburizing Process without Use of a Prior Gas Generator*
}

\section{Introduction}

Gas carburizing is the commonest case-hardening treatment to improve the fatigue strength and wear resistance of materials. In the conventional gas carburizing process, the furnace atmosphere is controlled to be at an optimum carbon potential with a mixture of the endothermic gas formed in the prior gas generator and the additional hydrocarbon gas. However, the conventional process has the following problems:

1) High cost for a large amount of endothermic gas

2) Extra energy for reheating endothermic gas that must be cooled at the outlet of the gas generator before transfer to the furnace

3) Costs for the gas generator

4) Complex system for atmosphere control system to optimize the carbon potential both in the gas generator and the carburizing furnace.

In order to overcome these problems, Mitsubishi Motors Corporation and Tokyo Heat Treating Co., Ltd. have developed a new gas carburizing process without use of a prior gas generator.

\section{Constraction of Heat Treat- ment Equipment}

Figure 1 schematically shows the construction of the heat treatment equipment for the new process, which is characterized by omission of a prior gas generator for producing the endothermic gas. The atmosphere is generated directly in the carburizing furnace from hydrocarbon gas and air.

\section{Features of New Process}

\section{Reduction of Gas Cost}

In the new process the catalytic effect is lower than in the conventional one. Therefore, the equilibrium of the furnace atmosphere should be attained by decreasing the flow rate of gas to stay in the furnace for a longer time. This decreased gas flow rate results in a significant reduction of gas consumption. Therefore the gas cost can be reduced by about one fifth compared with that in the conventional one.

\section{Improvement of Safety}

In general the continuous carburizing furnace consists of three

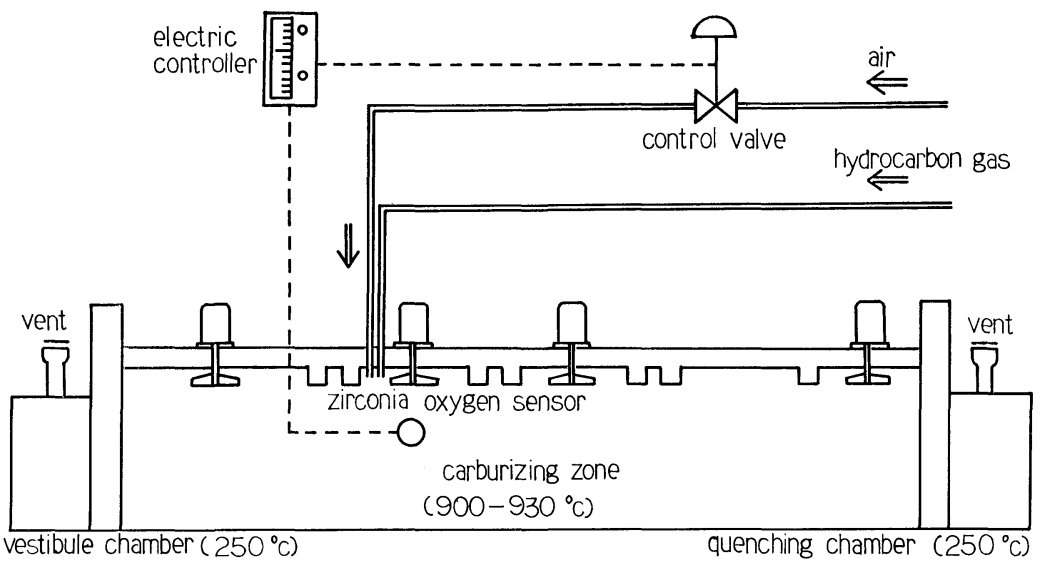

Fig. 1. Construction of heat treatment equipment. parts; a vestibule chamber, a carburizing zone, and a quenching chamber. Since the temperature in the two chambers are fairly lower than that in the carburizing zone, the gases in the chambers expand and contract upon opening and shutting the doors. The pressure in the chambers becomes negative after shutting the door because of the rapid cooling of the gases. While the pressure in the chambers is negative, explosion may occur if a large amount of fresh air is introduced into the chambers from the vents.

The potential danger of explosion can be completely avoided in the new process by combusting the natural gas at the entrance of the vents to prevent the introduction of fresh air.

\section{Precise Carbon Potential Control}

In the conventional process, the carbon potential is controlled by adjusting the flow rate of the additional hydrocarbon gas. Since the carbon potential is very sensitive to the amount of additional hydrocarbon gas, the fluctuation of carbon potential tends to be fairly large and the precise control is difficult. Moreover, this large fluctuation accelerates the deterioration of $\mathrm{O}_{2}$ sensors due to sooting. Consequently, the carbon content of the carburized layer often becomes higher than the eutectoid composition.

In order to overcome these problems, in the new process the hydrocarbon gas flow rate is fixed at a constant value and the carbon potential is controlled by adjusting the flow rate of air. The smaller fluctuation and the precise control of the carbon potential can be achieved by the present method.

\footnotetext{
* For further information, write to Production Engineering Department, Kyoto Works, Mitsubishi Motors Corporation, 1, Uzumasa Tatsumi-cho, Ukyo-ku, Kyoto 616. (C) 1987 ISIJ
} 